\title{
Information Modelling of Engineering Systems as an Improvement Factor for the Energy Efficiency of Building
}

\author{
Leonid Shilov ${ }^{1 *}$ and Liubov Shilova ${ }^{1}$ \\ ${ }^{1}$ Moscow state university of civil engineering, Yaroslavskoye shosse, 26, Moscow, Russia, 129337
}

\begin{abstract}
The article presents the analysis of the heat power of a heating system in accordance with valid normative documents. It also reveals some other factors influencing both the general heat balance of a building and its microclimate parameters but not taken into account in the analysis. The recommendations have been developed on the improvement of energy efficiency parameters of the buildings. The authors suggest some possible ways of solution of the problem of air-exchange disturbances due to the introduction of automation systems responsible for a continuous monitoring of climatic and micro-climatic conditions as well as for a combined regulation of heat-transfer agent and of fresh air inflow.
\end{abstract}

\section{Introduction}

Recently, both the home building industry and the foreign one have paid top priority attention to the improvement of energy efficiency of residential buildings. It was caused by high prices for power resources as well as by the deterioration of environment "[1]-[5]".

The improvement of energy efficiency of residential buildings reduces the heat losses by $15-25 \%$ for foundation and substructures, by $15-25 \%$ for walls, by $20-40 \%$ for windows, by $10-20 \%$ for roofing structures and by up to $30-35 \%$ for the ventilation equipment, respectively.

The reduction in heat losses may be achieved by the construction of energy-efficient buildings and structures as well as by the use of special technologies of control over the heat balance of buildings.

The article considers one of the key factors influencing the choice of ventilation and heating equipment - the climatic conditions of the building region - as the consumption of heat energy depends on the ambient air temperature. A proper control over the heat supply system is impossible without consideration of the dynamics of temperature changes.

\section{Methodology of analysis}

The climatic conditions in the regions of our country differ much, but every region has some common features, e.g. temperature conditions, average wind velocity, pressure values.

*Corresponding author: Leonid.A.Shilov@gmail.com 
In this connection, special regional maps for the Russian Federation territory have been developed in accordance with the climatic characteristics concerned (SP 20.13330.2011. Loads and effects (SNIP 2.01-07.85*).

The heat energy necessary for residential buildings is established through the Rules of normative energy consumption for communal services stated by the RF Government Decree №306 dated 23.05.2006, and it depends on the average daily ambient air temperature during the heating period. As a rule, the temperature values are taken from the building norms and rules or the climatic regional maps for the Russian Federation territory.

The main criteria of a proper operation of heat supply and ventilation systems for residential buildings are the following: heat balance, air balance and humidity balance. The general case of a heating system analysis is reduced to the solution of the heat balance equation.

The heat consumption of residential buildings is determined through the analysis methods which consider the factual heat-engineering characteristics of external enclosure structures and the normative air exchange values.

Neglecting the heat input due to the solar radiation, we can determine the heat power of the heating system for a typical room through the formula (1):

$$
Q_{H S}=Q_{H L}+Q_{\text {inf } / v e n t}-Q_{\text {dom }}
$$

$Q_{H L}$ - heat losses through the enclosure structures, W, which are determined by the formula (2):

$$
Q_{H L}=Q_{W A L L}+Q_{W I N D}
$$

The calculation of the optimum thermal resistance, the thickness of warmth-keeping material and the heat-transfer coefficient for enclosure structures is performed through SP 50.13330.2012. Here the required value of the thermal resistance $R_{0}^{r v}, m^{2} \cdot K / W$, of enclosure structures is calculated through the formula (3) with consideration of energy-saving conditions and depends on the degree-days of the heating period (DDHP):

$$
R_{0}^{r v} \rightarrow D D H P=\left(t_{i n}-t_{h p}\right) \cdot z_{h p}
$$

The formula (4) gives the required value of the heat-transfer resistance:

$$
R_{0}^{r v}=a \cdot D D H P+b
$$

where $\boldsymbol{a}$ and $\boldsymbol{b}$ - coefficients taken from the Appendix to SP 50.13330.2012 Heat insulation of buildings. or obtained through the interpolation.

The total heat losses through the structural elements $\sum Q_{T n}$ include main and additional losses which consider the additions $\beta_{i}$ and are calculated as the sum of heat losses through all the enclosure rooms by the formula (5):

$$
\sum Q_{\text {WALL/WIND }}=k_{0, i} \cdot F_{0, i} \cdot\left(t_{i n}-t_{e x 5}\right) \cdot n_{i} \cdot\left(1+\sum \beta_{i}\right), \mathrm{W}
$$

where ${ }^{k_{0, i}=\frac{1}{R_{0}^{v v}}}$ - the coefficient of the heat transfer through the enclosure element, $\mathrm{W} /\left(m^{2} \cdot K\right)$

$F_{0, i}$ - the design enclosure surface, $m^{2}$;

$t_{i n}, t_{\text {ex } 5}$ - the design temperature values inside and outside the room, ${ }^{\circ} \mathrm{C}$;

$n_{i}$ - the coefficient depending on the location of the external surface of the enclosure structure with respect to the ambient air (for windows and walls it is taken equal to 1);

$\beta_{i}$ - the coefficient considering additional heat losses as the parts of the main heat losses, and it depends on the orientation of building (it will be taken equal to 0.1 for the northern 
building side);

$Q_{\text {inf/vent }}$ - the greatest value of heat losses for the heating of the infiltration air or necessary for the compensation of the air outlet from the building, W. For the further calculations we take the maximum value of $Q_{\text {vent }}$ as there are practically no leakages in modern buildings.

For residential rooms, the heat expenditures for the heating of the infiltration air are taken not less than the values obtained by the formula (6):

$$
Q_{\text {vent }}=L_{\text {vent }} \cdot c_{a} \cdot \rho_{a} \cdot\left(t_{\text {in }}-t_{\text {ex } 5}\right) / 3.6, \mathrm{~W} \text {; }
$$

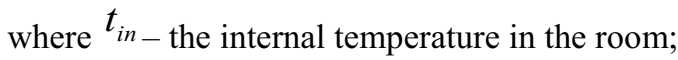

$t_{e x 5}$ - the temperature of the coldest 5 day-long period;

$c_{a}=1,005 \mathrm{~kJ} /(\mathrm{kg} \cdot \mathrm{K})$ - the specific heat of the air;

$\rho_{a}=1,2041 \mathrm{~kg} / \mathrm{m}^{3}-$ the density of the air;

$L_{\text {vent }}=l_{n} \cdot F_{f l}$, where $F_{f}$ - the surface of the floor in the heated room.

$l_{n}$ - the specific normative consumption of the incoming air taken as $l_{n}=3 \mathrm{~m}^{3} / \mathrm{h}$ for $1 \mathrm{~m}^{2}$ of residential area (the air circulation factor for the flat area of not more than $20 \mathrm{~m}^{2} /$ person ). The aforesaid parameters are established in the normative documents SP 54.13330.2011 Residential buildings (blocks of flats), the actual edition SNIP 31-01-2003.

For the calculation of the heat power of heating equipment we should consider the constant heat emissions in the rooms:

$$
Q_{\text {dom }}=q_{\text {dom }} \cdot F_{f l}, \mathrm{~W}
$$

where $q_{\text {dom }}$ - the specific domestic heat emission taken equal to $10 \mathrm{~W} / \mathrm{m}^{2}$,

$F_{f l}$ - the floor area in heated rooms.

This value is a constant; it does not depend on the ambient air temperature.

\section{An example of the analysis of the heat power of a heating system}

Let us consider a typical residential room with dimensions of $3 \times 4 \times 2.5 \mathrm{~m}^{3}$ and the window of $1.47 \times 1.55$ (the room looks north). In accordance with the formula (3), we obtain

$R_{0}^{r v} \rightarrow D D H P=(20+2.2) \cdot 205=4551$,

where $t_{\text {in }}=20{ }^{\circ} \mathrm{C}-($ GOST $30494-2011$ Residential and public buildings. Microclimate parameters in rooms);

$\mathrm{t}_{\mathrm{hp}}=-2.2^{\circ} \mathrm{C} ; \mathrm{z}_{\mathrm{hp}}=205$ days. - (SP 131.13330.2012 Constriction climatology).

we obtain the required heat-transfer resistance through the formula (4):

$R_{D D H P}^{r v}=2.8+\frac{3.5-2.8}{6000-4000} \cdot(4551-4000)=2.99\left(\mathrm{~m}^{2} \mathrm{~K} / \mathrm{W}\right)-$ for the wall;

$R_{D D H P}^{r v}=0.45+\frac{0.6-0.45}{6000-4000} \cdot(4551-4000)=0.49$

balcony doors.

$\left(\mathrm{m}^{2} \mathrm{~K} / \mathrm{W}\right)-$ for the windows and

In accordance with DDHP, the external wall should have the minimum required heattransfer resistance equal to $R_{0}=2.99 \mathrm{~m}^{2} \mathrm{~K} / \mathrm{W}$.

Calculate the total heat losses through the walls and windows in accordance with (5) 
$\sum Q_{\text {WALL }}=0.334 \cdot(2.6 \cdot 3.1-1.47 \cdot 1.55) \cdot(20-(-25)) \cdot 1 \cdot(1+0,1)=95.6 \mathrm{~W}$

$\sum Q_{W I N D}=2.04 \cdot(1.47 \cdot 1.55) \cdot(20-(-25)) \cdot 1 \cdot(1+0.1)=230.1 \mathrm{~W}$

And the total heat losses in accordance with (2)

$Q_{H L}=Q_{\text {WALL }}+Q_{\text {WIND }}=95.6+230.1=325.7 \mathrm{~W}$

The heat expenditures for the heating of ventilation air for this example is calculated through (6):

$Q_{\text {vent }}=36 \cdot 1.005 \cdot 1.2041 \cdot(20-(-25)) / 3.6=544.6 \mathrm{~W}$, with $L_{\text {vent }}=3 \cdot 12=36 \mathrm{~m}^{3} / \mathrm{h}$

The domestic heat emissions in this example are $Q_{\text {dom }}=10 \cdot 12=120 \mathrm{~W}$

As a result, we obtain $Q_{H S}=325.7+544.6-120=750.2 \mathrm{~W}$

To provide for the required microclimate $\left(+20^{\circ} \mathrm{C}\right)$ with the average temperature of the coldest 5day-long period $\left(-25^{\circ} \mathrm{C}\right)$ it is necessary to have the heat power of $750.2 \mathrm{~W}$. However, a wrong operation of the ventilation system causes a surplus heat power which upsets the heat balance.

Let us consider the dynamics characteristics of the required heat power, that is the operation of the heating system depending on the ambient air temperature. The results of the calculations through the aforesaid formulas are presented in Table 1; Fig.1 presents the heating system power output depending on the ambient air temperature.

Table 1. Heat Expenditures

\begin{tabular}{|c|c|c|c|c|c|c|c|}
\hline $\operatorname{tax},{ }^{\circ} \mathrm{C}$ & $\begin{array}{l}\mathrm{L}_{\text {vent, }} \\
\mathrm{m}^{3} / \mathrm{h}\end{array}$ & $\begin{array}{c}\text { Qvent, } \\
\text { W }\end{array}$ & $\begin{array}{c}\text { QwaLt, } \\
\text { W }\end{array}$ & Qwind, W & QHL, W & $\begin{array}{l}\text { Qdom, } \\
\text { W }\end{array}$ & $\begin{array}{l}\mathbf{Q}_{\text {cons }} \text { with } \\
\mathrm{L}_{\text {reat }}, \mathrm{W}\end{array}$ \\
\hline-30 & 36 & 605,1 & 106,2 & 255,6 & 361,9 & 120,0 & 846,9 \\
\hline-25 & 36 & 544,6 & 95,6 & 230,1 & 325,7 & 120,0 & 750,2 \\
\hline-20 & 36 & 484,0 & 85,0 & 204,5 & 289,5 & 120,0 & 653,5 \\
\hline-15 & 36 & 423,5 & 74,3 & 179,0 & 253,3 & 120,0 & 556,8 \\
\hline-10 & 36 & 363,0 & 63,7 & 153,4 & 217,1 & 120,0 & 460,1 \\
\hline-5 & 36 & 302,5 & 53,1 & 127,8 & 180,9 & 120,0 & 363,5 \\
\hline 0 & 36 & 242,0 & 42,5 & 102,3 & 144,7 & 120,0 & 266,8 \\
\hline 5 & 36 & 181,5 & 31,9 & 76,7 & 108,6 & 120,0 & 170,1 \\
\hline 10 & 36 & 121,0 & 21,2 & 51,1 & 72,4 & 120,0 & 73,4 \\
\hline
\end{tabular}

The analysis of the aforesaid data proves that the heating system does not reach its balance state because of permanent not-controlled and unpredicted changes in the ambient air temperature. 


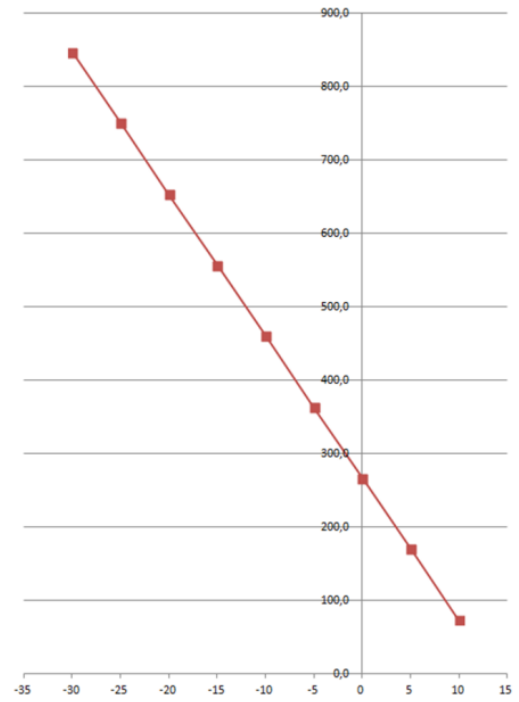

Qcons with Lvent, W - the real heat power consumption in case when the ventilation system operates properly

Fig.1. The heating system power depending on the ambient air temperature

Nowadays, the main kind of operation mode is the centralized control over the heat power output as it makes possible to use the minimum number of simple regulators for the normative temperature of hot water in the hot water supply systems.

It should be noted here that the heat power output in heat supply systems considers only one meteorology factor - the ambient air temperature - which is taken equal for all buildings under heat supply.

The problem of surplus heat emissions could be partly solved through the use of heating equipment with lock accessories (in accordance with SNIP 41-01-2003 and MGSN 3.01.01, the automated thermostatic regulation of the heat flows should be provided for). However, such regulation is possible only within a narrow temperature range.

When the thermoregulator is out of its operation range (as a rule, it happens when the windows are open), the delivery of heat-transfer agent is stopped. Thus, a wrong operation of the valve causes the decrease in the internal air temperature and the shut-down of heating system.

\section{Conclusion}

The aforesaid studies revealed some problems connected with the disturbances in the operation of heating supply and ventilation systems.

On the one hand, there is a problem of the air-exchange disturbance because of no infiltration through the windows; on the other hand, the surplus heat power causes the increase in the room temperature.

The required air-exchange may be provided for through the use of inlet valves. But it is necessary to consider the fact that any changes in the ambient air temperature require dynamic changes in the valve flow rate which is practically impossible nowadays.

At the same time, the factors influencing the heat supply requirements of buildings and their particular rooms are quite different; so it is practically impossible to consider them in the process of centralized regulation of the heat power output. In this connection, a combination of various regulation methods seems to be expedient. 
Here the measurement of internal microclimate parameters is very labourconsuming; it requires both the equipment and the qualification concerned.

In this connection, the next logical stage in the development of heating and ventilation systems should be the development and introduction of software considering the dynamics of changes in external and internal temperatures and including all-the-year-round operation cycle of the heating and ventilation systems. The further stage will be the creation of fully automated computer systems for a continuous monitoring of climate and microclimate parameters which perform a combined regulation of the heat-transfer agent and the ventilation.

\section{Acknowledgements}

This study was performed with the financial support of the RF Ministry of Education and Science (RF President Grant, agreement \#14.Z56.3456-MK).

\section{References}

1. S. Eleftheriadis, D. Mumovic, P. Greening, RSER, 67,811-825 (2017)

2. F.H. Abanda, L. Byers, E,97,517-527,(2016)

3. J.B. Kim, W. Jeong, M.J. Clayton, J.S. Haberl, W. Yan, AC, 50, 16-28 (2015)

4. G. Martinopoulosa, K.T. Papakostasb, A.M. Papadopoulos, EB,124, 79-87 (2016)

5. J. Vanus, P. Vojcinak, R. Martinek, M. Kelnar, Z. Machacek, P. Bilik, J. Koziorek,J. Zidek, PS, 7, 114-121 (2016) 